\title{
A construção viral da realidade: ciberpopulismos e polarização dos públicos em rede
}

\author{
The viral construction of reality: \\ cyberpopulisms and polarization of network audiences
}

\author{
Vania Baldi*
}

*Professor Auxiliar, Universidade de Aveiro, DigiMedia and Interaction Centre

Resumo

\begin{abstract}
O presente artigo visa analisar os desafios sociotécnicos e políticos representados pela fragmentação e polarização dos discursos públicos que atravessam os diferentes espaços info-comunicacionais. A opinião pública perspetiva-se como balcanizada por conflitos permanentes entre interpretações e tomadas de posição que dizem respeito a temas de relevância pública. Destaca-se como o intuito desses discursos não é o de gerar um diálogo entre interlocutores para chegar a uma plausível interpretação da realidade, mas o de tornar virais convicções preestabelecidas e assim acentuar o afastamento entre os grupos intervenientes.

Nesta perspetiva, afirma-se como os fenómenos sociais ficam transfigurados e pulverizados em micronarrativas radicais, abstratas e incoerentes, deturpando as noções de realidade e verdade. Dentro deste cenário é analisado como os media digitais, através dos seus diferentes filtros, algoritmos, affordances, bots, trolls etc., proporcionam uma intensificação e uma expansão da desordem informacional, que por sua vez se reflete numa ameaça para a vida democrática. Nesse sentido, a distorção dos conteúdos e das formas comunicativas são consideradas como emblemáticas e reforçativas das caraterísticas e tendências principais dos atuais movimentos populistas.

Comparando e articulando um conjunto de investigações, dados, hábitos e acontecimentos relativos ao fenómeno sociopolítico do populismo e ao tipo de literacia tecno-cultural predominante na infoesfera pretende-se enquadrar e analisar, através dum prisma interdisciplinar, os desafios societais representados pela emergente sobreposição de questões políticas, tecnológicas e culturais. Se apresentam no fim do texto iniciativas culturais, tecnológicas, jornalísticas e jurídicas que apontam para uma resposta construtiva e criativa à tendência sociotécnica e sociopolítica analisada ao longo do artigo.
\end{abstract}

Palavras-Chave: pós-verdade; cibercultura; populismo digital; desintermediação; polarização.

Abstract

This article aims to analyze the sociotechnical and political challenges represented by the fragmentation and polarization of the public discourses that cross the different information-communication spaces. Public opinion is viewed as balkanized by permanent conflicts between interpretations and positions that concern issues of public relevance. It is emphasized that the purpose of these discourses is not to generate a dialogue between interlocutors in order to arrive at a plausible interpretation of reality, but to spread preestablished convictions and thus accentuate the distance between the intervening groups. In this perspective, it is affirmed how social phenomena are transfigured and pulverized in radical, abstract and incoherent micronarratives, distorting the notions of reality and truth.

Within this scenario it is analyzed how the digital media, through its different filters, algorithms, affordances, bots, trolls etc., provide an intensification and an expansion of the informational disorder, which in turn is reflected in a threat to the democratic life. In this sense, the distortion of the contents and communicative forms are considered as emblematic and reinforcing the characteristics and main tendencies of the current populist movements.

Comparing and articulating a set of investigations, data, habits and events related to the sociopolitical phenomenon of populism and to the type of techno-cultural literacy prevailing in the infrasphere is intended to frame and analyze, through an interdisciplinary prism, the societal challenges represented by the emerging overlap of political, technological and cultural issues. Cultural, technological, journalistic and legal initiatives are presented at the end of the text, which point to a constructive and creative response to the sociotechnical and sociopolitical tendency analyzed throughout the article.

Keywords: post-truth; cyberculture; digital populism; disintermediation; polarization. 


\section{A construção viral da realidade}

O teor da crónica jornalística contemporânea, juntamente com os rumores pontualmente criados à volta dela que se espalham pelas redes sociais, testemunham os efeitos do curto-circuito político, tecnológico e cultural que permeiam o mundo da informação, a linguagem que o dinamiza e as discussões sociais que reflete, quer no contexto online, quer no offline. A chamada information disorder espelha uma falta de atenção e regulamentação sobre a qualidade dos conteúdos noticiosos e o modelo de negócio subjacente, acompanhando um clima político e cultural aparentemente cada vez menos disponível a uma reflexão aberta e ponderada sobre as várias questões sociais que marcam os desafios do nosso presente. Assistimos a um conjunto de debates, na esfera digital e política, que, frequentemente, carecem ou prescindem de referências concretas e lógicas na sua argumentação. Nesse cenário, parece pouco importante sustentar com factos e raciocínios fundamentados as tomadas de posição e as críticas sobre os problemas das sociedades contemporâneas.

A gramática das relações sociais, no cenário info-comunicacional pouco estruturado e racional, apresentase sob forma de contrastes polarizados entre grupos e/ou indivíduos que expressam sobre a mesma realidade interpretações muito diferentes ou, para utilizar um termo mais emblemático da atual semântica histórica, conceções da realidade "alternativas" e inconciliáveis, como se a realidade fosse algo factualmente sempre menos interessante, acessório e secundário (Sunstein, 2017).

Obviamente, aqui não se afirma que a realidade é passível de ser concebida como algo linear e monocromático e, portanto, simples de compreender. Pelo contrário, a sua ambivalência constitutiva é inevitavelmente terreno de conflitos entre várias maneiras de a querer representar e construir. De facto, como será percetível no fim desse mesmo texto, serão indicadas práticas culturais e projetos cívicos que emergem em resposta e contra-tendência com a lógica tecno-cultural predominante que aqui se procura desconstruir. O que aqui está em jogo é a primazia adquirida pelas interpretações em detrimento dos factos, incluindo nesses os dados estatísticos, os resultados das investigações científicas, a manifestação objetiva e tangível dos acontecimentos (tanto históricos como naturais), os efeitos concretos das políticas económicas ou das jurisdições (tanto nacionais como internacionais). Neste sentido, a esfera pública (sempre mais digital) é atravessada por polémicas inesgotáveis, onde, mais do que se procurar analisar em concreto os aspetos problemáticos da experiência histórica presente, e assim confrontar os vários pontos de vista que Ihe dizem respeito, a maioria dos intervenientes reage habitualmente de forma instintiva a tal complexidade, fechando-se em grupos com conviç̧ões e (re)sentimentos similares.

A complexidade dos enredos socioeconómicos, demográficos, ambientais, interculturais (entre os outros), resulta, nessa espécie de debates sem diálogos, frequentemente encarada como algo abstrato, fácil de se interpretar e resolver, já que não se pretende entrar nos detalhes dos fenómenos em análise. Dessa forma, pelas controvérsias sobre os temas de relevância pública não transparece o objetivo de aprender um caminho de interesse comum, "mas o de ganhar discussões ou o de confirmar uma convicção que já se tem" (Nichols, 2018, p. 162).

Neste sentido, podemos antecipar que dar prioridade às interpretações, em vez de à verificação dos factos, não remete para um debate epistemológico sobre limites e possibilidades da hermenêutica, mas, pelo contrário, para um ethos do conhecimento atrelado ao instinto e às emoções. Descobrimos assim, de uma forma nova e inesperada, que a sociedade da informação e do conhecimento tem gerado, também, um 
processo antirracionalista. Entrámos, desta forma, na sociedade dita de pós-verdade e no registo cultural das fake news "institucionalizadas". Não foi por acaso que o termo de pós-verdade entrou em 2016 no dicionário de Oxford referindo: "Relating to or denoting circumstances in which objective facts are less influential in shaping public opinion than appeals to emotion and personal belief". ${ }^{1}$

Porém, os comentários e as discussões mais virulentas não surgem sobre temas indiscriminados; antes surgem com mais frequência sobre algumas notícias específicas que protagonizam a agenda mediática e que permitem fomentar de forma memética os preconceitos contra determinados atores e assuntos sociais (políticos, cientistas, bancos, parlamentos, imigrados, vacinas, constituições, etc.).

Contudo, para entender tal repartição entre tópicos mais suscetíveis de gerar conflitos socio-comunicacionais temos que enquadrar, em paralelo, tal fenómeno, aparentemente focado na comunicação social e nos media digitais, dentro do cenário mais complexo e abrangente dos novos populismos políticos. Como poderemos ver a seguir, sem nos debruçarmos aqui sobre a vaga contestatária e antissistema, que se alastrou por diferentes setores da sociedade de muitos países ocidentais considerados detentores de uma sólida democracia, torna-se inviável uma compreensão adequada do que podemos chamar "construção viral da realidade" (Dal Lago, 2017).

\section{O populismo digital}

O cimento cultural que une os movimentos populistas é habitualmente identificado com um conjunto de tendências socioculturais: querer desconstruir tudo aquilo que simboliza uma cultura e uma prática de intermediação e representatividade políticas; denunciar a pressuposta falsidade das autoridades e entidades institucionais; ambicionar a estabelecer uma relação direta e imediata com o "povo", genericamente preconcebido como único, homogéneo e imune à impureza dos filtros jornalísticos, das estruturas verticais e da identidade multicultural; construir uma identidade política apostando enfaticamente em micronarrativas nem sempre coerentes, substituindo o marco ideológico pela fluidez do storytelling. Uma mistura de ressentimento social juntamente com pulsões racistas e de refutação dos símbolos político-institucionais do pluralismo democrático (Urbinati, 2016). Um intricado nó sociopolítico e cultural que se alimenta e reconhece através das "caixas de ressonância" que são os social media, as plataformas de microblogging e os sites dedicados à comunicação política.

Todavia, podemos verificar como, aparentemente, os movimentos populistas já não representam uma ameaça social, não são mais um ímpeto que atua na periferia do sistema político. De facto, o fenómeno populista tornou-se uma realidade institucional em vários países democráticos do Ocidente dito civilizado. Já não se trata de algo politicamente minoritário e sintomático de um mal-estar social que pode vir a rebentar revolucionando equilíbrios consolidados, mas de algo que veio agregar a maioria dos votos em muitos países, transformando o dissenso social em consenso eleitoral em muitos parlamentos ${ }^{2}$. Ainda não decorreu tempo

\footnotetext{
${ }^{1} \mathrm{https}$ ://en.oxforddictionaries.com/word-of-the-year/word-of-the-year-2016

2 Aqui nos referimos a um conjunto de países europeus com histórias políticas diferentes, mas que simultaneamente sofreram a emergência de movimentos e discursos políticos populistas baseados em uma ideia plebiscitaria da relação com os eleitores, assim conseguindo uma ampla representatividade eleitoral. O populismo é aqui encarado no sentido de Yves Meny e Yves Surel (2002), isto é, como ambivalência constitutiva da democracia dos países ocidentais que periodicamente polariza a ética dos discursos para objetivos diferentes. Nesse sentido, para além dos EUA, assistimos na Áustria, Itália, Finlândia, Suécia, Hungria, Inglaterra, Polonia em parlamentos fortemente condicionados por movimentos
} 
suficiente para entendermos qual a diferença entre a propaganda contestatária que caraterizou tais movimentos políticos e os programas de governação que a partir de agora deveriam orientar o sentido da sua atuação política.

As eleições democráticas que os partidos/movimentos populistas ganharam em muitos países determinaram uma clivagem entre uma retórica antissistema e uma necessidade de ter de o governar. Será então que as responsabilidades de governo irão descontinuar o seu estilo comunicacional e os seus métodos disruptivos com vocação anti-partidária? De qualquer forma, até ao momento atual, o que a nível transnacional têm em comum estas novas configurações governamentais remete para uma atuação política com traços específicos: 1) a identificação dos imigrantes como o inimigo comum (invocados como a causa da maioria dos problemas); 2) uma consequente defesa das fronteiras territoriais e socioeconómicas; 3) uma aversão ao cosmopolitismo, globalismo e às instituições que representam tal cosmovisão, a começar pela União Europeia (que, infelizmente, sabemos ter adquirido caraterísticas suficientes para desmentir de forma substantiva qualquer ideia de comunidade continental); 4) o objetivo de impor um estilo de governação baseado na performance decisória e focada no desrespeito pelo pluralismo partidário e pelos contrapoderes estabelecidos (as eleições são encaradas como plebiscitos que justificam o avassalamento das oposições e a "coroação" do líder); 5) uma tendência em afirmar um estilo propagandístico contestatário (mesmo estando no governo) - com os seus anúncios diretos ao povo (perspetivados como eleitores-soldados) sobre as decisões "radicais" a serem tomadas - em detrimento do exercício moderado e ponderado de comunicar e negociar com os outros atores político-sociais sobre a própria estratégia política. ${ }^{3}$

Tais pontos destacados encontram uma peculiar convergência com a cultura (mas seria mais correto dizer com a ilusão) da desintermediação digital. A ideia de uma sociedade do acesso sem distinções entre portas de entrada na rede, entre nós agregadores e distribuidores da informação, entre meios de viabilização do tráfego, tem fomentado práticas info-comunicacionais pouco cientes da verdadeira estrutura da infoesfera e dos filtros que estão por detrás da vida digital (Barabasi, 2002; Wu, 2011). Tal falta de atenção sobre os processos sociotécnicos e económicos que estão por detrás das normais práticas digitais tem tido o efeito de dificultar a formação de uma literacia digital madura e de corroborar o ethos indeterminista dos movimentos populistas.

Dando seguimento a esta lógica, muitos atores sociais (alguns com responsabilidades políticas e de informação) têm desafiado uma crença na horizontalidade e equivalência entre todas as entidades e sujeitos digitais, entre os vários pontos de vista e conhecimentos, dando azo a campanhas de viralização de conteúdos muitas vezes inconsistentes, mas consolidados no estilo e na propagação por serem encarados todos como dignos de atenção e simbólicos da reapropriação da palavra cidadã que, depois de uma época vivida como público mediaticamente silencioso, pode finalmente intervir para desmentir e fazer justiça contra os saberes e interesses ocultos das organizações "conspiradoras" (elites políticas e científicas, multinacionais, tribunais, grupos mediáticos).

de direita que revindicam maior autonomia decisória dentro do seu próprio país. Nesse cenário parlamentar tais movimentos alternam (de forma diferente conforme o pais) o respeito das leis constitucionais com a desobediência e ameaça contra alguns dos seus princípios constitutivos (a Polonia e Hungria se destacam pelos ataques aos direitos adquiridos pelos meios de informação e da magistratura de exercer com independência as suas funções, enquanto nos outros países a deriva autoritária - discursiva e política - ainda encontra-se balizada na aceitação das fundamentais regras e praxis institucionais).

${ }^{3}$ Um contributo importante sobre a tentativa de sistematizar o multifacetado panorama internacional dos populismos vem do livro organizado por Carlos De La Torre Global Populism (2018). 
A desintermediação proporcionada pelas redes sociais implicou, de facto, a tendência para nivelar a perceção das diferenças entre opiniões individuais e conhecimentos objetivos, desafiando aquele afastamento entre factos e interpretações que reforça um tipo de credulidade falaciosa em notícias sempre mais distorcidas e alteradas. Neste contexto, quem tenta desmentir um boato ou uma teoria pouco fundamentada (na linguagem jornalística referido como fazer debuking), é logo alvo de injúrias e acusações de cumplicidade com os conspiradores.

Deparamo-nos aqui, mais uma vez, face a um curto-circuito entre Web, aversão aos especialistas, valorização do autodidatismo e emergência de movimentos políticos produtores de storytelling à medida dos ressentimentos e dos estereótipos eleitoralmente mais rentáveis. Podemos então definir tal cruzamento entre imediatismo digital e imediatismo populista, como a origem do ciberpopulismo ou digital populism (Santoro, 2013; KhosraviNik, 2018).

\section{O colapso dos contextos online e a sua reemergência radicalizada}

Os aspetos até agora salientados remetem para as derivas mais radicais e representam as tendências mais perigosas, mas não enquadram os diferentes níveis de literacia democrática e digital atualmente presentes e operacionalizados na esfera pública em rede. Os curto-circuitos mencionados constituem, sem dúvida, uma dececionante surpresa com a qual é urgente confrontarmo-nos, sendo destacados em vários simpósios politico-culturais como o cerne dos desafios cívicos contemporâneos ${ }^{4}$.

Contudo, para além dos aspetos críticos mais estrondosos, sobre os quais voltaremos a refletir, merece a nossa melhor atenção o estabelecimento de uma nova gramática cultural diversamente incorporada nos vários comportamentos info-comunicacionais. Em primeiro lugar, temos que frisar como não há necessidade de se ser populista, fanático das conspirações ou trol/para se empolgar, ainda que inconscientemente, com atitudes (emotivas e cognitivas) reprodutoras do viés de confirmação (bias confirmation). Atitudes que se materializam em consequentes cybercascadese echo chambers, isto é, nos reforços dos preconceitos ligados à atração fatal entre grupos e indivíduos com as mesmas ideias preconcebidas, no isolamento e polarização entre grupos com cosmovisões alternativas.

De facto, numerosas investigações (Bikhchandani, Hirshleifer, Welch, 1998; Hirshleifer, 1999) refletem sobre os vieses de confirmação que acompanham as contraposições especulares entre "progressistas" e "conservadores" sobre, por exemplo, as temáticas ambientais, médicas e energéticas em contextos prédigitais. ${ }^{5}$ Nestes casos podemos considerar que não são as tecnologias digitais que criam as condições de

\footnotetext{
${ }^{4}$ Apesar de ser notória a relevância pública e académica adquirida pelos temas referidos, podem servir de exemplos alguns últimos simpósios realizados em diferentes partes do mundo por terem abordado os estes temas a partir de perspetivas heurísticas diferentes: Populism, Political Contention, and the Crisis of Democracy Symposium (publicado em https://www.pippanorris.com/cultural-backlash-1), AMINTAPHIL 2018 -- Democracy, Populism, and Truth (https://philevents.org/event/show/37338), CASBS Symposium: Populist Challenges to Democracy (https://casbs.stanford.edu/events/casbs-symposium-populist-challenges-democracy), Populism: what's next for democracy? Thursday 6 April \& Friday 7 April Symposium at the Institute for Governance and Policy Analysis (https://sydneydemocracynetwork.org/wp-content/uploads/2017/02/Populism-Symposium-6-April-2017.pdf), Global Populism and Democratic Futures Summit (https://uwaterloo.ca/global-engagement-program/events/summit), Movimientos populistas en Europa: la actualización del discurso totalitario en los medios de comunicación actuales y su repercusión en la opinión pública (http://comunicacionypensamiento.org/simposios/simposio21/).

${ }^{5}$ Em Timur Kuran e Cass Sunstein (1998) é demostrado como as provas científicas da não toxicidade dos OGM não são tradicionalmente aceites pelos progressistas norte-americanos, mas são-nos sobre a perigosidade das emissões de
} 
enviesamento dos factos, uma vez que estes são o resultado de preconceitos e influências sociais alheias ao mundo digital. As tecnologias digitais proporcionam a radicalização de posições contrapostas já existentes, assim como o desincentivo à auscultação recíproca e a indiferença às respetivas razões expressas e aos alegados conhecimentos. Em poucas palavras, o mundo interconectado revela-se (num sentido sociotécnico) inesperadamente alérgico ao pluralismo e produtor de uma série alargada de networked indivudualism (Welman et al, 2003).

As plataformas de redes sociais mais populares, de facto, funcionam e são desenhadas de uma forma tal que a sua affordance, conceito explorado pelo psicólogo da perceção James J. Gibson no seu livro seminal de 1979 (The Ecological Approach to Visual Perception), desafia a formação constante de clusters homogéneos e polarizados (Del Vicario et al, 2016). Neste sentido, as divisões e fragmentações que se seguem convergem com um dos desígnios dos líderes dos movimentos populistas, isto é, o do divide et impera. Os trolls e bots ativamente envolvidos sobre os discursos públicos mais controversos nos diferentes países ocidentais (saúde, religião, raça, segurança etc.) pretendem semear discórdia e hostilidade entre os grupos com visões contrapostas. ${ }^{6}$

O ambiente digital, apesar da familiaridade que inspira e com a qual gerimos os nossos perfis e as nossas tarefas quotidianas, é uma esfera indeterminada de produção de conteúdos e interações onde os contextos estão em rede, mas colapsados, as audiências são invisíveis e tudo o que se diz ou faz pode ser retirado facilmente das circunstâncias de interação (boyd, 2014). Esta falta de perceção de contexto favorece uma desconsideração (ou ignorância) das razões que animam a produção de cada texto.

Assim, é fácil para quem vai em busca de conteúdos e posições em sintonia com as suas, utilizar e combinar da forma que mais lhe agrada os documentos que vai encontrando sem verificar a sua proveniência e consistência. Um elemento que desafia e torna tal prática mais vulgar é, como veremos a seguir, o da aceleração do tempo social em rede, das suas práticas de informação e interação e, portanto, da consequente escassa retenção de conhecimento e elaboração conceitual.

O que, paradoxalmente, perverte a ideia originária do ciberespaço como lugar de democratização do conhecimento, acrescentando uma dimensão de maior e geral conflitualidade social, é a visibilidade e aparente evidência de todas as narrativas que se afirmam nesse espaço. Se acreditarmos que online $1=1$, temos, então, que acreditar que um jornal é igual a qualquer outro jornal e a palavra de um especialista é igual à de uma pessoa qualquer? Como costumava lembrar Isaac Asimov, a ideia que a democracia significa que a ignorância de um cidadão vale o mesmo que o conhecimento de um outro é uma ideia falsa e, também, nefasta. ${ }^{7}$

De facto, como foi assinalado pela politóloga Anne Pluta no seu Trump Supporters Appear to Be Misinformed, Not Uninformed(2016), é preciso distinguir entre os tipos de públicos e as situações em que esses públicos sem contexto atuam: "os cidadãos desinformados não dispõem de qualquer informação, enquanto os que

carbónio, e vice-versa pelos conservadores. O conhecimento científico é aproveitado conforme as ideologias e as esferas de interesses (económicas e eleitorais) em jogo.

${ }^{6}$ Por exemplo, no recente artigo publicado pelo "American Journal of Public Health" (AJPH) é lançado o alerta sobre a militarização da informação de saúde a poluir a opinião pública com notícias falsas. Broniatowski, David A. et all (2018) Weaponized Health Communication: Twitter Bots and Russian Trolls Amplify the Vaccine Debate (disponível em https://ajph.aphapublications.org/doi/10.2105/AJPH.2018.304567)

${ }^{7}$ Isaac Asimov "A Cult of Ignorance", em Newsweek, 21 de janeiro, 1980, p. 19. (disponível em https://aphelis.net/cultignorance-isaac-asimov-1980/ 
estão mal informados dispõem de informação que contraria os dados conhecidos e a opinião dos especialistas". ${ }^{8}$

Estamos, portanto, perante uma peculiar sobreposição de conflitos desencadeados por um discurso público radicalizado e fragmentado, onde os confins entre propaganda, alteração da realidade, conhecimento estabelecido e invenção de factos parecem evaporar-se, desafiando uma construção da realidade baseada em notícias e comentários virais, constantemente percecionados como suspeitos e acusados de serem manipulados. Como afirma Tom Nichols no seu A morte da Competência. Os Perigos da Campanha Contra o Saber Estabelecido:

Pensava-se que anos de melhoria do ensino, o acesso facilitado aos dados, a explosão das redes sociais e remoção dos obstáculos à participação no debate público iriam melhorar a nossa capacidade de deliberar e decidir. Pelo contrário, parece que estas mudanças tornaram tudo pior. Qualquer informação pública sobre qualquer assunto descamba numa guerra de trincheiras, em que o objetivo mais importante é o de provar que a outra pessoa está enganada (Nichols, 2018, p. 63).

\section{As armadilhas da cultura smart e a ideologia da inovação disruptiva}

Um exemplo paradigmático da convergência entre a morfologia dos movimentos populistas e a das literacias que se desenrolam online revela-se a partir da análise das práticas digitais mais espalhadas e comuns no nosso quotidiano digital. Trata-se de práticas que refletem e ao mesmo tempo desafiam uma experiência online guiada pela velocidade e automatização impostas pelos dispositivos digitais, tanto num âmbito lúdico como no ligado à formação e à investigação (aliás, o protagonismo ganho na última década pelos infotainment e edutainment diz muito relativamente ao clima cultural cujos contornos estamos a tentar traçar).

Neste sentido, uma pesquisa pioneira que merece ser mencionada, How Are We Searching the World Wide Web? A Comparison of Nine Search Engine Transaction Logs, dos autores Bernard Jansen e Amanda Spink (2006), relata uma tendência exemplar nos hábitos de busca de informações on-line testados num intervalo de sete anos sobre um total de 287 milhões de sessões em Internet analisadas através de nove motores de busca e mais de um bilhão de queries.

A esmagadora maioria dos utilizadores da Web procura e acede aos conteúdos digitais, dizem-nos os investigadores, através queries de apenas uma palavra e durante um tempo de poucos minutos (apenas 5, no $70 \%$ dos casos). Preguiça e pressa na busca, confiança cega na lista dos resultados e adesão às respostas que mais sintetizam qualquer assunto problemático, são valores incorporados na práxis digital que entregam aos intermediários das plataformas (considerados transparentes) e dos motores de busca (tão eficazes, porque rápidos) um poder enorme de condicionamento da organização do conhecimento e das práticas quotidianas. Um cenário ideal e convergente, portanto, com qualquer estratégia de governamentabilidade

${ }^{8}$ Pluta, A. (2016) Trump Supporters Appear to Be Misinformed, Not Uninformed, in https://fivethirtyeight.com/features/trump-supporters-appear-to-be-misinformed-not-uninformed/) (visitado em 29/06/18) 
tecno-económica (tecnocracia aumentada), mas também com a lógica da "prestação" (Han, 2014) dominante no mundo do trabalho e da formação.

Neste sentido, refletindo sobre quais as condições culturais mais propícias para a construção de anticorpos ao populismo digital, se quiséssemos investir na política cultural e na formação deveríamos deixar de lado a ideia, até agora adotada pela maioria das empresas e instituições públicas, de confundir o saber e o conhecimento com as competências técnicas e funcionais, porque se assim fosse viveríamos já num mundo mais civilizado, equitativo e aberto ao pluralismo. Na realidade, habitando um mundo estruturalmente "onlife" (Floridi, 2013), o desenvolvimento cultural e o incremento da literacia tecnológica deveriam convergir na promoção constante da compreensão histórica dos fenómenos sociais e no desafio de saber lidar com as transformações de longa duração atuando no seu meio de forma crítica e criativa.

Todavia, o enfoque colocado na marquetização da aprendizagem, pensada em função da empregabilidade flexível e adequada às exigências da competição do mercado, proporcionou a predominância de outros tipos de discursos mais focados no fetiche da novidade. Emblemático desse tipo de axiomas tecno-culturais e tecno-económicos, que foram incorporados também nas instituições que os deviam desconstruir, é um recente manifesto pela inovação científica apresentado por Clayton Christensen e Michael Horn - da Business Administration da Universidade de Harvard e do Instituto para a Disruptive Innovation. No livro que editaram, Disruptive Class: How Disruptive Innovation Will Change The Way the World Learns, o adjetivo disruptive, embora pretenda evocar a noção de "destruição criadora" do economista austríaco Joseph Alois Schumpeter, é utilizado pelos dois professores Norte-Americanos para propagandear e desafiar uma necessária mudança de estatuto do ensino superior. Se para Joseph Alois Schumpeter a disrupção é algo que ocorre sempre, e precisa ser enquadrada no âmbito da complexidade económica, no discurso de Christensen e Horn torna-se um imperativo moral com implicações naturalmente positivas, introduzindo o conceito numa perspetiva neodarwiniana. Seguindo o mesmo raciocínio, num artigo recentemente publicado no New York Times, Innovation Imperative: Change Everything. Online Education as an Agent of Transformation, os dois autores voltam a promover a atividade do Instituto Disruptive Innovation retomando a história da navegação e remetendo para os efeitos da inovação tecnológica dentro do mesmo contexto marítimo. Para os dois autores, as Universidades vivem a mesma situação crítica já experienciada pelos navios a vapor no começo do século XIX. ${ }^{9}$ Os navios que não se atualizaram e não adotaram nova tecnologia deixaram de ser competitivos nos atravessamentos oceânicos.

O paralelismo entre navios e Universidades é surpreendente: as Universidades que não implementarem tecnologias de forma disruptiva no seu método de ensino/aprendizagem estarão destinadas a desaparecer, tal como os barcos à vela que foram suplantados pelas embarcações a vapor. Poderemos considerar adequada tal comparação? Será que as Universidades devem transportar mercadoria como os barcos? Ou trata-se de mais uma distorção do sentido originário dos conceitos e contextos para reforçar e justificar o interesse em afirmar uma política cultural focada nos "meios sem fins"(Agamben, 1996)?

O que aqui interessa sublinhar é a estratégia argumentativa dos que promovem a inovação tecnológica como forma (disruptiva e competitiva) de potenciamento (sem especificar qual o seu telos) implícito dos conteúdos, das metodologias de ensino e da formação dos alunos. E naturalmente, qualquer tipo de efeito colateral imprevisto e indesejado remediar-se-á através da mesma inovação tecnológica. A literacia que aqui

${ }^{9}$ http://www.nytimes.com/2013/11/03/education/edlife/online-education-as-an-agent-of-transformation.html? $\mathrm{r}=0$ 
se vende não é a literacia crítica e cultural, mas apenas a que mais facilmente se articula com os interesses económicos do momento, aquela que Bernard Stiegler referiu como pertencer ao processo da "deformação pragmática da inteligência em astúcia" (Stiegler, 2014).

Querer inovar no domínio educativo, que é gravíssimo não o considerar como alavanca para uma cultura cívica e democrática, implicaria partir da reflexão sobre os padrões cognitivos e os valores simbólicos abrangidos e contemplados pela cultura do acesso e da aceleração típicas da híper-conexão digital. Para poder facultar uma diferente abordagem didática nos diferentes graus de ensino (negociando sempre com os atores sociais envolvidos: instituições de ensino, associações de pais, associações estudantis, associações de professores, estudiosos de cultura digital e grupos juvenis), seria necessário confrontar-se com as transformações antropológicas que a híper-conexão digital desencadeou. As primeiras preocupações deveriam ser as de investigar sobre as redes sociais e tecnológicas dentro das quais se criam os hábitos cognitivos e info-comunicacionais que caraterizam a App Generation. ${ }^{10}$ Por exemplo, como veremos a seguir, um dos desafios formativos, na perspetiva de quem promove a análise crítica dos comportamentos online como sintomáticos de uma nova estrutura psíquica-coletiva, seria o de criar anticorpos tecnológicos e culturais nas novas gerações, nos seus processos de aprendizagem e de participação no mundo digital por via dos atalhos constantemente proporcionados pelas otimizações algorítmicas das plataformas digitais.

Os atalhos que as aplicações digitais fornecem (a cultura do smart), as perguntas e respostas automatizadas repetidamente prestadas pelos serviços dos diferentes sites, o registro e a computação cruzada de todos os dados possíveis e imagináveis transfigurados pelo targeting numa nova estratégia de proximidade entre empresas, Estados e consumidores, representam uma heurística fundamental para a compreensão dos desafios societais do tempo presente. A força sedutora das mensagens dos líderes populistas faz parte destes desafios, uma vez que se baseiam na oferta retórica de soluções simples e definitivas para problemas complexos.

\section{A democracia na era dos Social Clicks}

O elo entre populismo e Web, como referido acima, reforça-se sempre que a simplificação, os atalhos tecnológicos e conceituais se padronizam como práticas de comunicação e informação online. Se por um lado torna-se imperativo perceber a relação entre as reações emotivas aos conteúdos digitais e 0 capital cultural dos internautas no que diz respeito aos temas morais, políticos e sociais que protagonizam as disputas em rede, por outro torna-se fundamental perceber se tais reações não são sintomáticas, também, de uma mudança antropológica gerada pela cibercultura.

Neste sentido, em sintonia com os estudos já mencionados, demostrou-se que o tempo médio para decidir sobre a credibilidade de um website é de 2,30 segundos (Robins \& Holmes, 2008). Websites de domínio privado com informações relativas à saúde, finança, às políticas públicas, proteções de dados, vendas de

\footnotetext{
${ }^{10}$ Nesse estudo, The App Generation: How Today's Youth Navigate Identity, Intimacy, and Imagination in a Digital World, que cruza a investigação psicológica com a sociológica e artística, os dois autores (Howard Gardner e Katie Davis, 2013) comparam as atitudes críticas e criativas entre alunos norte-americanos (dos diferentes níveis de ensino) da época digital com os da época anterior. Os dois autores salientam as tendências dos alunos da atual época digital em atuar e pensar pelos "atalhos". Rápidos e tecnicamente competentes em criar/editar cenários imagéticos, mas banais e simplistas em imaginar enredos narrativos.
} 
casas, viagens, seguros etc. Informações sobre as quais deveríamos decidir fazendo apelo ao nosso sentido pragmático e orientados pelos nossos interesses específicos, mas que apesar disso são retidas precipitadamente. Como poderíamos, então, debater de forma séria e aprofundada sobre conteúdos, ligados à vida cívica e democrática, retirados através de uma atenção pré-reflexiva? O que está em jogo é, de facto, a estruturação de um novo habitus percetivo e cognitivo que desafia escolhas e preferências cada vez menos vinculadas a ponderações circunspectas, mas a uma libido antecipatória típica de uma estética definida como premediation (Grusin, 2010).

Outro exemplo que nos confirma a emergência de tal atitude pré-reflexiva é refletido na pesquisa Social Clicks What and Who Gets Read on Twitter (Gabielkov et al., 2016), onde se constata que o 59\% dos utilizadores do Twitter retwuittam sem terem lido o texto do tweet. Na mesma linha vai a pesquisa sobre as votações dos posts no Reddit, Identifying and Understanding User Reactions to Deceptive and Trusted Social News Sources (Glenski et al., 2017), onde foi testado que $78 \%$ dos supostos leitores costuma tomar posição sobre os posts sem ler os textos correlacionados. Apesar de tudo, nessas duas pesquisas emerge uma curiosa atenção por parte dos utilizadores sobre os comentários ao retweets e às votações, como se interessasse mais a tónica das observações para decidir com qual dos trends alinhar. Estas atitudes instintivas e reativas testemunham uma paradoxal busca de contexto, uma vez que o que é mais tomado em conta é o enquadramento dos juízos pró ou contra os textos objeto de partilha e divulgação.

Todavia, tais experiências pré-reflexivas, ao espelhar o sistema nervoso dos públicos em rede, remetem também para o design das interfaces com as quais nos deparamos constantemente. Quem projeta os dispositivos e os seus programas aposta num determinado tipo de uso e gratificação do utilizador, isto é, o da Intermittent Variable Rewards. Foi o designer Tristan Harris (ex-Google design ethicist) que, no seu How Technology is Hijacking Your Mind -from a Magician and Google Design Ethicist (2016), confirmou como o propósito de uma Web-Company é o de reforçar a dependência dos utilizadores do acesso aos seus produtos info-comunicacionais. Segundo o designer, os nossos tiques de pegar frequentemente no smartphone, espreitar as notificações, fazer scrol/ ou refresh nas páginas dos nossos perfis nas redes sociais ou na caixa de email, correspondem ao almejado efeito de slot machine que qualquer App ou Website pretende atingir. Todas as vezes que tocamos nos nossos dispositivos, controlamos, abrimos e fechamos as páginas que nos dizem respeito estamos, conforme a affordance perspetivada, a atuar como se acionássemos a manivela de uma slot machine, com a adrenalina assente em intermittent variable rewards ("alguém me interpelou?" "alguém se está a lembrar de mim?" etc.).

Este conjunto de estudos, que remetem para tendências comportamentais em rede sem cair em generalizações dogmáticas, confirma a lição de Marshall McLhuan, o qual caraterizava cada era tecnológica através das suas repercussões antropológicas no sistema de perceção e cognição, isto é, no sistema nervoso dos seres humanos coevos. Uma abordagem em linha com a do habitus e das techniques du corps estudada por Marcel Mauss (1936), segundo o qual os seres humanos adotam de forma pré-consciente, por proximidade e contágio com as relações e as atividades que tecem o nosso habitat quotidiano (e, portanto, não por compreensão lógica), padrões de perceção, cognição e ação.

A rede de relações que engendra tais padrões comportamentais abrange seres humanos e objetos (Latour, 2005), tudo aquilo com o que interagimos e cria as condições objetivas e implícitas da nossa (co)existência. A vida onlife, com os seus relatos, gadgets e interesses automatizados, solicita e predispõe, também, 
(re)ações baseadas no imediatismo, na fragmentação, no timeless time, na sobreposição infindável e exterminada de inputs informativos.

O estado de saúde de cada democracia implicaria uma opinião pública (já transfigurada em emoção pública) sustentada no reconhecimento e na partilha de um mundo comum (ainda que repleto de desigualdades). Porém, a fragmentação e dispersão da atenção, juntamente com a criação ad hoc de narrativas e disputas radicalizadas sobre temas socialmente divisivos, com relatos muitas vezes alheios aos factos empiricamente constatáveis, determinam a necessidade de repensar as preocupantes formas que a democracia veio a adquirir.

Ademais, juntamente com a necessidade de analisar as transformações tecno-antropológicas (com o relativo caos de narrativas polarizadas que transportam consigo), é importante instituir outras formas e instrumentos de análise crítica, direcionada contra o tipo de autoritarismo que está sedeado na administração de bases de dados aparentemente acéfalas (isto é, sem centro de gestão), constantemente reconfiguradas e orientadas para emoldurar os comportamentos e afetos dos atores sociais e das suas relações. A hegemonia, hoje em dia, é disputada através de armas de destruição matemática. ${ }^{11}$

A democracia pode vir a ser perspetivada como uma tecnologia smart? As constituições serão traduzidas em softwares constantemente implementados por algoritmos na definição articulação e atuação de novas políticas públicas? São, estes últimos, cenários tecnológicos e políticos que abrem um novo horizonte problemático para a gestão das desigualdades e dos conflitos sociais, onde a natureza e a posse das informações (os dados) sobre as quais se estabelecem as políticas e as tomadas de decisão (sugeridas por automatismos) representarão o terreno ético-político das lutas futuras (Greenfield, 2017).

\section{A Cibercultura como teatro de lutas políticas e económicas}

Seria fácil, então, pensar que a contemporânea vaga de populismos a que assistimos tem o seu embrião nesta dimensão cibercultural até recentemente ignorada, que agora ameaça pôr em causa o ideal socialmente emancipatório que nos foi prometido com o acesso ao mundo digital. Como alertou Christian Fuchs (2018), a proliferação dos nacionalismos e autoritarismos evoca um passado recente, parecendo confirmar o receio de que a história se repita, ao mesmo tempo que experienciamos fenómenos que prometem uma nova era, resultantes de tecnologias como os social media, os big data, a Internet das Coisas, a cloud computing, entre outros. O velho e o novo parecem interligar-se no presente em formas particularmente complexas.

É verdade que finalmente, na era 2.0 , as audiências puderam cumprir um desígnio de maior visibilidade, passando a protagonizar a vida mediática. Também é verdade, como já referimos, que deu origem, infelizmente, à legitimação tecno-cultural das opiniões fast food atreladas às emoções instantâneas e aos preconceitos preestabelecidos. A outrora proclamada sociedade da informação e do conhecimento parece revelar-se uma sociedade em que tudo é automaticamente registado e transfigurado pelo targeting.

\footnotetext{
${ }^{11}$ Esta é uma importante reflexão de Cathy O'Neil sobre a emergência de novos poderes despóticos interligados à gestão dos big data, no seu livro de 2016: Weapons of Math Destruction: How Big Data Increases Inequality and Threatens Democracy.
} 
A Web 2.0 ficou um território ocupado pelas gigantescas empresas que atuam de forma monopolista e que, de facto, abrangem, computam, corelacionam e pulverizam os vários detalhes da vida de cada um de nós. O que essas empresas pretendem é o máximo apego aos dispositivos e serviços tecnológicos disponibilizados e promover assim o maior tráfego digital possível dentro dos seus walled gardens (Wu, 2011).

A partir destes pressupostos económicos e comerciais, os vários utilizadores e públicos em rede são considerados como infindáveis nichos de mercado, cuja relevância radica em serem constantemente monitorizados para afunilar qualquer tipo de predição e antecipação na oferta de serviços e conteúdos (Pariser, 2012). Os algoritmos da personalização desafiam um círculo vicioso onde o que o código sabe acerca de nós passa a ser a fonte do nosso ambiente mediático. E o nosso ambiente mediático condiciona as nossas preferências e escolhas futuras.

Assistimos, assim, não apenas a uma questão que é problemática, na medida em que radica em informações incorretas e maldosas, mas também com o comodismo que este processo nos pode trazer.

A transformação tecnológica não deve, contudo, ser encarada como o fator determinante da crise da racionalidade dialógica e da deterioração do contexto democrático. Os seus possíveis efeitos na emergência das polarizações culturais e dos populismos são igualmente filtrados por narrativas e visões do mundo ideológicas que também contribuem para a definição da Internet de hoje como terreno de conquista política e económica.

Por exemplo, Yascha Mounk, no seu livro The People vs. Democracy: Why Our Freedom is in Danger and How to Save It, dedica uma parte das suas reflexões ao papel desempenhado pelos social media, mas no quadro de um contexto bem mais complexo. A primeira questão que o estudioso salienta é a virtude dos mass media (os generalistas da era pré-digital) por terem evitado (nos EUA e na Europa ocidental) a difusão de ideias extremistas, selecionando com cuidado informações falsas ou manipuladas e alimentando valores de relevância pública. Porém, podemos acrescentar, tal época mediática enquadrava-se num contexto de boom económico, dentro de sociedades caraterizadas por fluxos migratórios moderados e conflitualidades interétnicas controláveis, com um estado social ainda sólido e uma confiança geral na inteligibilidade do telos histórico.

De qualquer forma, o que Yascha Mounk considera que está mais associado à emergência dos movimentos populistas é, de um lado, o "liberalismo antidemocrático", isto é, a tecnocracia, um sistema antidemocrático que delimita a liberdade democrática dos países; e, do outro, o "iliberalismo democrático", por exemplo, as vontades populares que contrariam as decisões jurídicas (o autor cita o veto à construção de novos minaretes em mesquitas na Suíça decidido por referêndum, contrariamente ao que estava expresso na constituição vigente). Mas o desafio mais crítico e epocal radica nos dados comparados sobre a perda progressiva de confiança nas instituições democráticas e nos políticos, quer ao nível ocidental, quer global. De facto, se, nos anos setenta, $40 \%$ dos eleitores norte-americanos tinham confiança nos membros do Congresso, agora apenas 7\% se declara confiante (Mounk, 2018, p. 117).

Estes dados adquirem um sentido mais profundo e alarmante quando o autor os cruza com as tendências das novas gerações (nos países de tradição liberal) se sentirem indiferentes face ao risco de uma possível deriva autoritária. Assistimos, assim, à constituição de uma "geografia cultural" do populismo, onde os media digitais apenas representam um fator exógeno ao fenómeno, o qual parece remete-nos para causas e questões histórico-sociais mais profundas.

Contudo, existem sinais de como as sociedades estão a reagir aos desafios mencionados. Por exemplo, numa vertente jurídica podemos salientar uma nova atenção transnacional direcionada para as fake news 
que visam "envenenar" a opinião (emoção) pública. Neste sentido, o tribunal belga condenou o ex deputado Laurent Loius a visitar campos de concentração nazistas por negacionismo. A sentença, para além da condenação administrativa, previu que o político belga de extrema direita, depois de cada visita a um campo de concentração, escrevesse um texto de pelo menos cinquenta linhas sobre o que ia vendo nos campos e sobre as emoções provocadas. Foi ainda condenado a publicar cinco relatos na sua página Facebook, após cada viagem. ${ }^{12}$

Também em Itália, o Tribunal da cidade de Modena condenou e multou uma associação "no-vax" (movimento contra as vacinas, presente em vários países) por ter redigido e divulgado pela cidade um cartaz com estatísticas incorretas sobre os efeitos das vacinas. A condenação veio no seguimento de uma queixa do Centro de Saúde da cidade italiana referida. ${ }^{13}$

Muitos jornalistas desmentiram em muitas circunstâncias boatos virais sobre as condições dos migrantes dentro dos navios. Por exemplo, que os refugiados passem o tempo dentro dos navios que os transporta para as costas europeias jogando videojogos. ${ }^{14}$ Uma jornalista a bordo do barco da ONG "Open Arms" desmentiu e divulgou as notícias falsas que circulavam nas redes sociais sobre as condições socioeconómicas de uma refugiada (Josefa), acabada de ser resgatada no Mediterrâneo, por ter sido fotografada com as unhas pintadas. Algo que foi reconstruído pela jornalista demostrando que aquelas unhas (caso fossem um grave indicador de bem-estar) tinham sido pintadas a bordo pelos ativistas e assistentes sociais para transmitir um sinal de conforto e de início de recuperação. ${ }^{15}$

Existem muitíssimos laboratórios jornalísticos e associações de informação que nos últimos anos começaram a trabalhar para contradizer e contornar a viralização e adulteração de conteúdos mediáticos com iniciativas transnacionais de sensibilização e ensino, iniciando colaborações entre instituições privadas e públicas, quer em rede, quer nas diferentes realidades locais. ${ }^{16}$

\section{Conclusões}

Existem, portanto, projetos sociotécnicos que visam travar o maniqueísmo populista incrementado pelo uso malicioso dos social media. Verificamos como uma das razões que justifica a divulgação e a persistência das mentiras em rede assenta na inercia dos preconceitos (que só almejam confirmar-se a si próprios), mas uma outra razão remete para a falta de literacia (auto)crítica. São fatores emendáveis e que não deveriam desencadear júbilos apocalíticos (típicos de uma teoria crítica pelo gosto da crítica, isto é, aquela que costuma desenhar cenários socioculturais compactamente miseráveis esquecendo-se, por exemplo, que

\footnotetext{
${ }^{12}$ https://www.gazetadopovo.com.br/blogs/caixa-zero/politico-belga-nega-holocausto/ (visitado em 12/01/18)

${ }^{13}$ https://bologna.repubblica.it/cronaca/2018/07/13/news/modena prima condanna in italia ai no vax per fake new s-201632035/ (visitado em 07/08/18)

${ }_{14}$ Para prejudicar a missão do navio humanitário "Aquarius" espalhou-se a notícia que os refugiados não necessitam de nenhuma ajuda, pois estão sempre colados aos seus gadgets tecnológicos. https://maldita.es/maldito-bulo/los-bulossobre-los-refugiados-y-migrantes-del-aquarius/ - https://www.elconfidencial.com/tecnologia/2018-06-18/refugiadosaquarius-moviles-africa 1580372/

${ }^{15}$ http://www.askanews.it/esteri/2018/07/21/long-open-arms-sbarca-josefa-in-spagna-e-porta-il-caso-in-tribunaletop10 20180721 175023/ (visitado em 01/08/18)

${ }^{16}$ As iniciativas valiosas são numerosíssimas, aqui referimos apenas umas das internacionalmente mais populares: a checkology do the news project literacy, os recursos online GoogleImages - YoutubeDataViewer - VerificationHandbook; o site de fact-checking snopes.com (the definitive Internet reference source for urban legends, folklore, myths, rumors, and misinformation); o projeto jornalístico colaborativo cross-check.com ou o First-Draft.....
} 
quem está a exercer análise crítica não é uma exceção do seu tempo, mas a confirmação que aquela realidade não seja nem tão compacta nem tão miserável $)^{17}$, nem atitudes entregues ao chamado espírito do tempo.

Do lado da tecnologia digital, sabemos que o modelo de negócio dos media é sempre aquele orientado para os anúncios. Neste sentido, como afirmado pelo CEO da Medium.com (Evan Williams (2017), "..a pressão para produzir mais conteúdos e mais baratos compromete a profundidade, a originalidade e a qualidade". Mas também sabemos que tecnologicamente existe muito conhecimento que poderia ser utilizado para reorientar esta tendência ao consumo rápido e compulsivo dos conteúdos digitais. Assim como a nossa experiência percetiva e cognitiva, privada e pública, é condicionada por softwares e algoritmos que são criados para fazer clicar, partilhar e editar o mais rapidamente possível conteúdos presentes nas demais plataformas, também podemos almejar experiências que, num sentido contrário, sejam propiciadas por outros algoritmos concebidos para estimular uma reflexividade diferente acerca das próprias atividades e atitudes onlife.

Por exemplo, como sugere Tim O'Reilly (2018), todas as vezes que clicamos para partilhar rapidamente uma informação poderíamos logo receber uma notificação a dizer-nos: "Tem a certeza de que quer partilhar este link? Não parece ter lido a história", ou: "Quer partilhar antes de verificar se é confiável?" (p. 298). Estes são exemplos de como a tecnologia digital, se regulamentada ou reorientada para finalidades não comerciais, pode ter efeitos culturais mais saudáveis e promissores para os utilizadores que somos todos nós. Exemplos que se tornaram, em muitos casos, aplicações e plataformas digitais facilmente utilizáveis e distribuídas em setores de nicho, projetos com finalidades cívicas que apenas necessitariam de uma maior publicitação (pois, marketing), consideração e adesão para se propagarem mais (openideo.com, witness.org, humanetech.com, duckduckgo.com, entre muitos outros). A mudança cultural passa pelas práticas sociais que também a tecnologia (regulamentada ou não) proporciona.

Temos também que considerar com a máxima atenção os conflitos que, por vezes, se manifestam dentro das grandes empresas digitais. Existem sinais de como, até no coração do império oligopolista da Silicon Valley, se levantam questões éticas ligadas com as condições do trabalho (Amazon e Apple, por exemplo) e com a deontologia que deveria guiar os seus projetos editoriais. Neste último caso destaca-se a agitação organizada por milhares de trabalhadores da Google contra a parceria estabelecida entre a empresa e o Pentágono americano para desenvolver projetos conjuntos de inteligência artificial com finalidades militares, assim como contra a vontade do top management da empresa de aceitar os filtros da censura chinesa para entrar no mercado chinês. ${ }^{18}$

É possível, e já acontece em contextos diversos, desarticular as caixas de ressonância onde costumamos estanciar, promover conexões com grupos que fazem da discussão e do exercício da dúvida sobre o que nos é constantemente oferecido pelos media digitais o seu método de participação, desencadear uma

\footnotetext{
${ }^{17}$ Um exemplo típico dessa abordagem elitista e autocomplacente é o recente artigo Notícias do paraíso digital, de António Baião e António Pedro Marques, no $2^{\circ}$ número da bela revista "Electra" (2018). A argumentação é a de considerar a Web como uma rede protagonizada pela "estupidez" e, também, "estúpidos" todos aqueles que são reféns de uma visão simplista e determinista da realidade, não chegando a perceber como esta seja sempre multifacetada e complexa. É pena que os juízos expressos em bloco sobre o "paraíso digital", a cultura que lhe subjaz e os seus atores sofram da mesma cegueira epistémica, uma vez que acabam por ser pouco abertos em reconhecer as suas ambivalências, contradições e contra-tendências internas, assim como o constante dinamizar-se de projetos alternativos que nesse híper-contexto crescem.

${ }_{18}$ Google Employees Protest Secret Work on Censored Search Engine for China (em https://www.nytimes.com/2018/08/16/technology/google-employees-protest-search-censored-china.html).
} 
tendência comum a exercitar a perplexidade como ética propicia a uma melhor compreensão do que está em jogo revalorizando o interesse pelos factos verídicos. ${ }^{19}$ Finalmente, mais cedo ou mais tarde, teremos que apreender a desaprender o hábito de fazermos corresponder as nossas práticas aceleradas e instintivas aos inputs digitais produzidos à nossa medida e teremos que questionar abertamente os slogans estereotipados daqueles ciberpopulismos assentes na fabulação enfática da realidade. Para mudar a realidade é preciso começar da realidade.

Combater contra as injustiças, disfunções socioeconómicas, socioculturais e sociotécnicas deve implicar o reconhecimento de que a mudança é a única constante da história e que sabemos menos do que julgamos. Se cairmos na armadilha propiciada pelos líderes (ciber)populistas, isto é, a do divide et impera, cuja polarização radical entre ideias (muitas vezes preconcebidas) espelha a estratégia, perderemos a ocasião para sairmos dessa espiral que não tem alguma finalidade civilizacional.

\section{Referências Bibliográficas}

Baião, A., Marques, A.P. (2018) Notícias do paraíso digital, em "Electra" Vol. 2, Lisboa: Fundação Edp, 7486.

Barabasi, L. (2002) Linked. How everything is connected to everything else and what it means for business, science, and everyday life New York, Plume Books.

Bikhchandani, S., Hirshleifer, D., Welch, I. (1998) Learning form the Behavior of Others: Conformity, Fads, and Informational Cascades, em «Journal of Economic Perspective», Vol. 12, 151-170.

boyd, d. (2014) It's Complicated: The Social Lives of Networked Teens. Yale: University Press.

Broniatowski, David A., et all (2018) Weaponized Health Communication: Twitter Bots and Russian Trolls

Amplify the Vaccine Debate (disponivel em:

https://ajph.aphapublications.org/doi/10.2105/AJPH.2018.304567)

Christensen, C. e Michael, H. (2016) Disruptive Class: How Disruptive Innovation Will Change The Way the World Learns, New York, Mcgraw-Hill.

Dal Lago, A. (2017) Populismo Digitale. La Crisi, la Rete e la Nuova Destra, Milano, Raffaello Cortina Editore De La Torre, C. (2028) Global Populism. London, Routledge Handbook.

Del Vicario, M., Bessi, A., Zollo, F., Petroni, F., Scala, A., Caldarelli, G., Stanley, E., Quattrociocchi, W. (2016) The Spreading of Misinformation Online, «Procedings of the National Academy of Science», Vol. 113 (3), 554-559.

Floridi, L. (2013) The onlife manifesto, Oxford: Springer.

Fuchs, C. (2018) Digital Demagogue: Authoritarian Capitalism in the Age of Trump and Twitter. London: Puto

\footnotetext{
${ }^{19}$ Nesse sentido é promissor o recente relatório do "Pew Research Center" sobre The Political Environment on Social Media, onde é referida, para além de uma certa frustração pela tónica desrespeitosa e insultuosa das interações nas redes sociais, uma grande apreciação dessas plataformas como "valuable tools for political action and discussion", onde quase um terço dos utilizadores "feel that social media sites do 'very well' at bringing new voices into the political discussion $(31 \%)$ or helping people get involved with issues that matter to them $(30 \%)^{\prime \prime}$. http://www.pewinternet.org/2016/10/25/the-political-environment-on-social-media/
} 
Gabielkov, M., Ramachandran, A., Chaintreau, A., Legout. A, (2016) Social Clicks: What and Who Gets Read on Twitter?, em ACM SIGMETRICS / IFIP Performance 2016, Jun 2016, Antibes Juan-les-Pins, France. 〈hal-01281190〉

Gibson, J. J. (1979). The Ecological Approach to Visual Perception. Boston: Houghton Mifflin.

Glenski, M., Weninger, T., Volkova, S. (2018) Identifying and Understanding User Reactions to Deceptive and Trusted Social News Sources, (disponível em https://arxiv.org/abs/1805.12032)

Greenfield, A. (2017) Radical Technologies. The Design of Everyday Life, London: Verso.

Grusin, R. (2010)_Premediation: Affect and Mediality After 9/11, Palgrave Macmillan.

Han, B-C. (2014) A Sociedade do Cansaço, Lisboa: Relógio D’Água.

Harris, T. (2016). How Technology is Hijacking Your Mind-from a Magician and Google Design Ethicist, (disponível em https://medium.com/thrive-global/how-technology-hijacks-peoples-minds-from-amagician-and-google-s-design-ethicist-56d62ef5edf3)

Hirshleifer, D. (1999) The Blind Leading the Blind, em Tomassi M. e Ierulli, K. (Orgs) «The New Economics of Human Behavior», Cambridge.

KhosraviNik, M. (2018). Social Media Techno-Discursive Design, Affective Communication and Contemporary Politics. In "Fudan Journal of the Humanities and Social Sciences", Vol. 11 No 3. Spinger Berlin Heidelberg, 1-16.

Kuran, T., Sunstein, C. R. (1998) Availability Cascades and Risk Regulation, em «Stanford Law Review», Vol. 51 (р. 683-768).

Latour, Bruno (2005). Reassembling the social: an introduction to actor-network-theory. Oxford-New York: Oxford University Press.

Meny, I., Surel, Y. (2002). Democracies and the Populist Challenge. London: Palgrave.

Mauss, M. (1936) Les techniques du corps, em Journal de Psychologie, XXXII, No 3-4, 15 mars - 15 avril.

Mounk, Y. (2018) The People vs. Democracy: Why Our Freedom is in Danger and How to Save It, Harward: University Press

Nichols, T. (2018) A Morte da Competência, Lisboa, Quetzal.

O'Neil, C. (2016) Weapons of Math Destruction: How Big Data Increases Inequality and Threatens Democracy. New York: Crown.

O’Relly, T. (2018) Como será o futuro e porque depende de nós, Lisboa: Dom Quixote

Pariser. E. (2012) The filter bubbles: What the Internet Is Hiding from You. New York: Penguin Press

Pluta, A. (2016) Trump Supporters Appear to Be Misinformed, Not Uninformed, em FiveThirtyEight.com (https://fivethirtyeight.com/features/trump-supporters-appear-to-be-misinformed-notuninformed/)

Santoro, G. (2013). Un Grillo qualunque. Il Movimento 5 Stelle e il populismo digitale nella crisi dei partiti. Roma: Castelvecchi.

Jansen, Spink, Pedersen (2006) How Are We Searching the World Wide Web? A Comparison of Nine Search EngineTransaction Logs. In "Information Processing and Manegament: An International Journal", n² 42, 248-263.

Stiegler, B. (2014) Digital studies: organologie des savoirs et technologies de la connaissance. Limoges: FYP Editions.

Sunstein, C.R. (2017) \# Republic. Divided Democracy in the Age of Social Media. Princeton: University Press. 
Urbinati, N. (2016) The Antiegalitarian Mutation: The Failure of Institutional Politics in Liberal Democracies. New York: Columbia University Press.

Wellman, B., Quan-Haase, A., Boase, J., Chen, W., Hampton, K., Díaz, I. and Miyata, K. (2003), The Social Affordances of the Internet for Networked Individualism, em "Journal of Computer-Mediated Communication", Vol. 8, No 3. https://doi.org/10.1111/i.1083-6101.2003.tb00216.x

Williams, E. (2017) Renewing Medium's Focus, em "Medium", 4 de Janeiro de 2017, (disponível em https://blog.medium.com/renewing-mediums-focus-98f374a960be)

Wu, T. (2011) The Master Switch: The Rise and Fall of Information Empires, New York: Knopf. 